Achilles tendons and returned to top level athletics simply by the use of the heel inserts and no other management. One thing is abundantly clear to me. 30 out of $\mathbf{4 0}$ of the patients that I have studied had used heel raises for their Achilles tendonitis, in some cases for as long as six years. All of these still have their symptoms and yet by removing their heel raise and inserting a small energy absorbing material in its place their symptoms were resolved. $A$ heel raise is not the appropriate form of treatment for Achilles tendonitis. It does not remove the tension from the Achilles tendon at the point of heel strike. When it does work it only does so because it provides efficient energy absorption.

Finally, may I say that the physical properties of Sorbothane as used in the heel inserts and insoles will be supplied on request by the marketing company to doctors and therapists engaged in the treatment of patients with heel strike associated conditions.

The motives behind the challenge seemed far from clear to me and it would command little respect from the thousands of athletes around the world who have used these heel inserts and insoles with remarkable benefit. Finally I would say that there is no such thing as scientific proof in medicine. One case cured is proof as far as that patient is concerned and any control trial where one of the body senses are left completely uncontrolled, in this case proprioception, is wide open to scepticism. I am afraid this situation will have to be proved by personal experience and traditional clinical trials are not an appropriate way of studying these phenomena.

Yours sincerely,

GORDON E. MacLELLAN, FRCS

Royal National Orthopaedic Hospital, 234 Great Portland Street, London W1N 6AD

\title{
CORRESPONDENCE
}

3 Bridge Avenue,

Maidenhead,

Berkshire,

UK

To the Editor:

Dear Sir,

\section{VISCO-ELASTIC HEEL SUPPORTS}

I read with interest the article in Volume 15 page 117. Being a practicing Podiatrist I find the management of subcalcaneal pain and Achilles tendonitis by Sorbothane visco static heel cushions together with orthotics is a remarkable therapy. However, I am writing to warn your readers that other appliances than those described in the article are being marketed.

In a personal letter to me from the originator of the study, Mr. G. E. Maclellan, FRCS, he stated he has not been consulted in any way regarding the manufacture or quality control or provision for medical data, supportive literature, etc. by any firm other than EIM, who provided the appliances described in the article. It may be therefore that these products possibly are inferior to those marketed by IEM and practitioners should be sure of the type they are using with regard to patient care and management.

Yours sincerely,

David R. C. Bell, MChS, SRCh 